Virginia Commonwealth University VCU Scholars Compass

2008

\title{
Interaction of gas molecules with Ti-benzene complexes
}

G. Chen

Virginia Commonwealth University

P. Jena

Virginia Commonwealth University, pjena@vcu.edu

Y. Kawazoe

Tohoku University

Follow this and additional works at: http://scholarscompass.vcu.edu/phys_pubs

Part of the Physics Commons

Chen, G., Jena, P., Kawazoe, Y. Interaction of gas molecules with Ti-benzene complexes. The Journal of Chemical Physics 129, 074305 (2008). Copyright (C 2008 AIP Publishing LLC.

\section{Downloaded from}

http://scholarscompass.vcu.edu/phys_pubs/191

This Article is brought to you for free and open access by the Dept. of Physics at VCU Scholars Compass. It has been accepted for inclusion in Physics Publications by an authorized administrator of VCU Scholars Compass. For more information, please contact libcompass@vcu.edu. 


\title{
Interaction of gas molecules with Ti-benzene complexes
}

\author{
G. Chen, ${ }^{1}$ P. Jena, ${ }^{1}$ and Y. Kawazoe ${ }^{2}$ \\ ${ }^{1}$ Department of Physics, Virginia Commonwealth University, Richmond, Virginia 23284, USA \\ ${ }^{2}$ Institute for Materials Research, Tohoku University, Aoba-ku, Sendai 980-8577, Japan
}

(Received 3 June 2008; accepted 18 July 2008; published online 18 August 2008)

\begin{abstract}
Using first-principles calculations based on gradient corrected density functional theory, we have studied the interaction of $\mathrm{NH}_{3}, \mathrm{H}_{2}$, and $\mathrm{O}_{2}$ with Ti-benzene complexes $\left[\mathrm{Ti}(\mathrm{Bz})_{2}\right.$ and $\left.\mathrm{Ti}_{2}(\mathrm{Bz})_{2}\right]$. The energy barriers as the gas molecules approach the Ti-benzene complexes as well as the geometries of the ground state of these interacting complexes were obtained by starting with several initial configurations. While $\mathrm{NH}_{3}$ and $\mathrm{H}_{2}$ were found to physisorb on the $\mathrm{Ti}(\mathrm{Bz})_{2}$ complex, the $\mathrm{O}_{2}$ reacts with it strongly leading to dissociative chemisorption of the oxygen molecule. In contrast all the gas molecules react with the $\mathrm{Ti}_{2}(\mathrm{Bz})_{2}$ complex. These studies indicate that the reaction of certain, but not all, gas molecules can be used to probe the equilibrium geometries of organometallic complexes. Under special conditions, such as high pressure, the $\mathrm{Ti}$ atom intercalated between benzene molecules in $\mathrm{Ti}(\mathrm{Bz})_{2}$ and the $\mathrm{Ti}_{2}(\mathrm{Bz})_{2}$ complexes could store hydrogen in chemisorbed states. The results are compared to available experimental data. (C) 2008 American Institute of Physics.
\end{abstract}

[DOI: $10.1063 / 1.2969108]$

\section{INTRODUCTION}

The interaction between metal atoms and organic molecules has been a topic of great interest in organometallic chemistry for a long time. However, a fundamental understanding of the structure of these systems and, in particular, how and where the metal atoms bind to the organic molecules has been difficult to discern due to problems associated with solvents. The ability to make clusters of the organometallic complexes by varying both the number of metal atoms and organic molecules independently in the gas phase has made it possible to achieve this understanding. Many experiments ${ }^{1-6}$ have been carried out in recent years that involve mass spectra, fragmentation channels, and electronic properties of transition and nontransition metal atoms interacting with different organic molecules. Since no experiments in the gas phase are able to directly describe the geometry of these complexes, indirect methods have often been employed. One such method is the study of the interaction of clusters with known gases and inferring geometries based on the reaction products. For example, Kaya and co-workers described a technique where transition metal-benzene complexes were reacted with $\mathrm{NH}_{3}$. They found that among $\mathrm{M}_{x}(\mathrm{Bz})_{y}$ complexes, where $\mathrm{M}$ is an early transition metal atom $(\mathrm{Sc}-\mathrm{V})$, those with $x=y$ reacted while those with $y=x$ +1 did not. The authors suggested that these complexes have a sandwich structure, where the metal atoms are intercalated between the benzene molecules. For clusters with $x=y$, one metal atom is always exposed and hence can react, while for complexes with $y=x+1$, all the metal atoms are sandwiched between organic molecules and hence they are not exposed to the reactant molecules. The authors used $\mathrm{CO}$ and $\mathrm{NH}_{3}$ as reacting gases. No theoretical studies have been carried out to study these reactions and confirm the experimental hypothesis. In addition, it is not clear if this suggestion is universal in the sense that it applies to all reagent gases or is it specific to $\mathrm{CO}$ and $\mathrm{NH}_{3}$ ? Pandey et al. ${ }^{7}$ reported a comprehensive theoretical study of these complexes and confirmed the sandwich structure. However, no theoretical study has been reported on the interaction between the reagent gas molecules and the adsorbed metal atoms in these complexes.

In this paper, we provide the results of a theoretical study of the interaction of $\mathrm{NH}_{3}, \mathrm{H}_{2}$, and $\mathrm{O}_{2}$ molecules adsorbed on $\mathrm{Ti}(\mathrm{Bz})_{2}$ and $\mathrm{Ti}_{2}(\mathrm{Bz})_{2}$ complexes. The metalorganic complexes describe two model systems-first, where one of the metal atoms is exposed, and second, where all the metals atoms are sandwiched between organic molecules. The reasons for selecting $\mathrm{NH}_{3}, \mathrm{H}_{2}$, and $\mathrm{O}_{2}$ are as follows: (a) calculations on $\mathrm{NH}_{3}$ will complement the experimental study; (b) $\mathrm{H}_{2}$ molecules are small and steric hindrance may not be a major obstacle in allowing these molecules to react with metal atom sandwiched between the benzene molecules. In addition, several studies ${ }^{8-12}$ have recently shown the promising ability of metal decorated polymers to store hydrogen. (c) Most metals exposed to air oxidize. Do the metal atoms oxidize when they are sandwiched between organic molecules? In the following a detailed study of the physical and chemical adsorption processes of $\mathrm{NH}_{3}, \mathrm{H}_{2}$, and $\mathrm{O}_{2}$ on Ti-Bz complexes and the reaction paths between different states are presented. In addition to achieving a fundamental understanding of the interaction between the metal atoms and benzene, the results may shed light on their potential applications.

\section{DETAILS OF CALCULATIONS}

The calculations of binding energies and equilibrium structures were carried out using first-principles method based on the spin-polarized density functional theory (DFT), ${ }^{13,14}$ as implemented in the Vienna ab initio simulation package (VASP). ${ }^{15-19}$ We have employed the projector augmented-wave method. ${ }^{17,18}$ The exchange-correlation con- 
tribution to the potential is calculated using the generalized gradient approximation prescribed by Perdew-Wang (PW91). ${ }^{20,21}$ The solution of the Kohn-Sham equations is performed by an efficient matrix diagonalization technique based on a sequential band-by-band residual minimization method. ${ }^{16}$ A supercell with edge length of $18 \AA$ is used in the calculations, which is large enough to eliminate the interaction between a complex and its periodic images. The charge density and the local potential are calculated using a $150 \times 150 \times 150$ mesh. The wave functions are expanded in a plane wave basis with an energy cutoff of $400.0 \mathrm{eV}$, which has been shown to be sufficient for Ti. ${ }^{17-19}$ Only the $\Gamma$ point in the supercell is used in the summation of the Brillouin zone. The optimization is stopped when the forces acting on each atom reach the force tolerance of $0.02 \mathrm{eV} / \AA$.

We first discuss the accuracy of the DFT for treating Ti-benzene complexes since it has been pointed out by Rabilloud $^{22}$ that the ground state spin multiplicity of early transition metal-benzene complexes calculated using multireference configuration interaction (MRCI) calculation is at odds with those predicted by DFT. ${ }^{7}$ For example, the spin multiplicity of $\mathrm{VBz}$ complex calculated by Pandey et al. ${ }^{7}$ using DFT yielded a sextet state ground state, while that using $\mathrm{MRCI}^{22}$ leads to a quartet state. Note that the energy difference between adjacent spin multiplicity states is close in energy and is sensitive not only to approximations in exchange and correlation potential but also to choice of basis sets. Kandalam et al. ${ }^{23}$ showed that the ground state of the VBz complex using Lanl2dz basis set yields a spin quartet ground state, while that using a $6-311 \mathrm{G}^{* *}$ yields a spin doublet ground state, although both calculations were performed within the framework of DFT. The energy difference between the two spin states lies in the $0.3 \mathrm{eV}$ energy range. However, this sextet state conflicts with the results of Yasuike et al. ${ }^{6}$ Yasuike et $a l^{6}{ }^{6}$ used a configuration-averaged self-consistent-field method which is similar in concept to that of the state-averaged multiconfiguration self-consistentfield (MCSCF) method of Rabilloud. ${ }^{22}$ While both authors predicted a spin quartet ground state for $\mathrm{VBz}$, the energy differences between the spin quartet and spin doublet states are found to be $0.44 \mathrm{eV}$ by Rabilloud and $0.05 \mathrm{eV}$ by Yasuike et $a l .{ }^{6}$ Using DFT and the projector augmented-wave method as implemented in the VASP code, we found the VBz ground state to have a spin doublet electronic configuration, which agrees with the Gaussian 6-311 $\mathrm{G}^{* *}$ result of Kanadalam et $a l .{ }^{23}$ We also calculated the ground state spin multiplicity of TiBz complex using the method described above. Our computed spin multiplicity of 5 is in good agreement with the calculation of Yasuike et al. ${ }^{6}$ who used a quantum chemical approach. For the $\mathrm{Ti}(\mathrm{Bz})_{2}$ and $\mathrm{Ti}_{2}(\mathrm{Bz})_{2}$ complexes studied in this paper, we calculated them to be singlet and quintet states, respectively.

To further confirm the accuracy of our method, we calculated the binding energies and structural parameters of $\mathrm{TiH}$, TiO, TiN, and $\mathrm{H}_{2} \mathrm{Ti}=\mathrm{NH}$ molecules. The interatomic distances of Ti-H, Ti-O, and Ti-N in the diatomic molecules are calculated to be $1.75,1.63,1.59 \AA$, and the length of $\mathrm{Ti}-\mathrm{H}$, Ti-N in $\mathrm{H}_{2} \mathrm{Ti}=\mathrm{NH}$ molecule are calculated to be 1.76 and $1.68 \AA$, respectively. The datum is in good agreement with the experimental Ti-O bond length of $1.62 \AA{ }^{24}$ The calculated $\mathrm{Ti}-\mathrm{H}$ and $\mathrm{Ti}-\mathrm{N}$ bond lengths in $\mathrm{H}_{2} \mathrm{Ti}=\mathrm{NH}$ molecule also agree well with those calculated using MCSCF method, ${ }^{25}$ namely, 1.81 and $1.70 \AA$ A. The binding energies of $\mathrm{TiH}, \mathrm{TiO}$, and TiN molecules are calculated to be 2.62, 7.69, and $5.45 \mathrm{eV}$, which also agree well with the experimental values $^{24}$ of 2.12, 6.97, and $4.93 \mathrm{eV}$, respectively. These comparisons provide enough confidence in the accuracy of our computational technique. In addition, we should point out that while the binding energies and ground state spin multiplicites derived from various theoretical methods may differ, the equilibrium geometries are seldom sensitive to these choices. In this paper we are particularly interested in the structure of $\mathrm{TiBz}$ complexes as they react with gas molecules.

\section{RESULTS AND DISCUSSIONS}

The geometrical structures of Ti-benzene complexes with adsorbed gas molecules were obtained without imposing any symmetry constraint. For initial configurations we considered the molecules to bind to the Ti-Bz complexes in three possible ways: physisorption where the molecule is weakly bound; molecular chemisorptions where the molecular bonds are slightly stretched and binding is stronger than that in the physical adsorption state; and dissociative chemisorptions where the binding is the strongest and gas molecules dissociate and bind atomically. The reaction paths between different adsorption states were studied in detail. In Figs. 1, 3, and 5 we mark these configurations with symbols $P, \mathrm{MC}$, and DC which represent, respectively, gas molecules bound in physisorbed state, molecular chemisorbed state and dissociative chemsorbed state. For each of these states, the molecules were initially allowed to approach the Ti-Bz complexes along the two different directions; the first one, denoted by symbol $V$, corresponds to the direction parallel to the $\mathrm{C}$ atom, while the second one, denoted by symbol $B$, corresponds to the direction parallel to the $\mathrm{C}-\mathrm{C}$ bridge. These starting configurations are marked $\mathrm{PB}, \mathrm{PV}, \mathrm{MCV}$, MCB, DCV, and DCB in Figs. 1, 3, and 5. For each of these starting configurations, we optimized the structures fully without symmetry constraint. In the following the results for each of the molecule interaction are discussed separately.

\section{A. $\mathrm{NH}_{3}$ adsorbed Ti-benzene complexes}

The optimized geometrical configurations of $\mathrm{NH}_{3}$ adsorbed on $\mathrm{Ti}(\mathrm{Bz})_{2}$ and $\mathrm{Ti}_{2}(\mathrm{Bz})_{2}$ complexes are shown in Figs. 1(a) $-1(\mathrm{j})$, respectively. The binding energies, $\Delta E$ $=E\left(M_{x} \mathrm{Bz}_{y}\right)+E\left(\mathrm{NH}_{3}\right)-E\left(M_{x} \mathrm{Bz}_{y} \mathrm{NH}_{3}\right)$, for each of the configurations are listed in Fig. 1. Note that positive binding energy means that the complex is bound while negative binding energy relates to unstable configuration. Energetically $\mathrm{NH}_{3}$ prefers to bind to $\mathrm{Ti}(\mathrm{Bz})_{2}$ in the physisorbed state (see the configurations marked PV and PB sates) with the geometry marked PV having marginally higher binding energy than that marked $\mathrm{PB}$. The binding energy of the configuration marked PV is $60 \mathrm{meV}$, while that marked $\mathrm{PB}$ is $40 \mathrm{meV}$. The molecular chemical adsorption states MCV and MCB as well as the dissociative chemisorption adsorption states DCV 


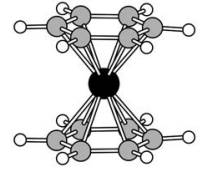

a), $P V, E_{\mathrm{b}}=0.06 \mathrm{eV}$

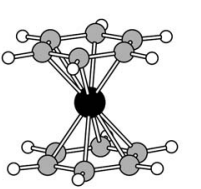

d), $P B, E_{\mathrm{b}}=0.04 \mathrm{eV}$

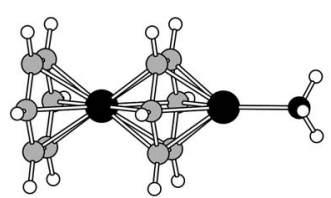

g), $M C V, E_{\mathrm{b}}=1.11 \mathrm{eV}$

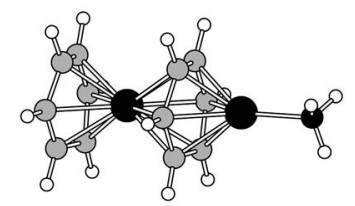

i), $M C B, E_{\mathrm{b}}=1.02 \mathrm{eV}$

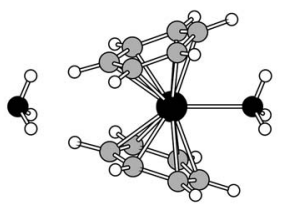

b), $M C V, E_{\mathrm{b}}=-0.09 e V$

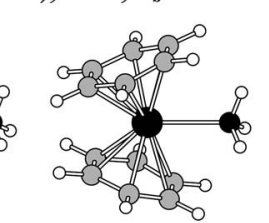

e), $M C B, E_{\mathrm{b}}=-0.13 e V$

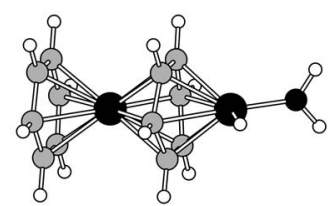

h), $D C V, E_{\mathrm{b}}=2.18 \mathrm{eV}$

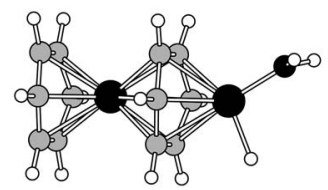

$j), D C B, E_{\mathrm{b}}=2.15 \mathrm{eV}$
FIG. 1. The optimized geometries of $\mathrm{NH}_{3}$ adsorbed on Ti-benzene complexes. The white, the gray, the big black, and the small black balls represent $\mathrm{H}, \mathrm{C}, \mathrm{Ti}$, and $\mathrm{N}$ atoms, respectively. (a) and (d) are the physisorption states for $\mathrm{Ti}(\mathrm{Bz})_{2}$; (b) and (e) are the molecular chemisorption states for $\mathrm{Ti}(\mathrm{Bz})_{2}$; (c) and (f) are the dissociative chemisorption states for $\mathrm{Ti}(\mathrm{Bz})_{2} ;(\mathrm{g})$ and (i) are the molecular chemical adsorption states for $\mathrm{Ti}_{2}(\mathrm{Bz})_{2}$; and $(\mathrm{h})$ and $(\mathrm{j})$ are the dissociated chemical adsorption states for $\mathrm{Ti}_{2}(\mathrm{Bz})_{2}$.

and DCB of $\mathrm{NH}_{3}$ have negative binding energies and hence are unstable. The interatomic distance between $\mathrm{Ti}$ and $\mathrm{N}$ in both PV and PB states is found to be $\sim 5.62 \AA$, which is much longer than the sum of the atomic radii of $\mathrm{N}$ and $\mathrm{Ti}$ atoms (the atomic radii of $\mathrm{Ti}, \mathrm{N}$, and $\mathrm{H}$ atoms are 1.40, 0.65, and $0.25 \AA$ ). ${ }^{26}$ This result is in agreement with experimental finding that $\mathrm{NH}_{3}$ does not interact with $\mathrm{Ti}_{n} \mathrm{Bz}_{n+1}$ complexes.

For $\mathrm{NH}_{3}$ interacting with $\mathrm{Ti}_{2}(\mathrm{Bz})_{2}$, the situation is entirely different. Here both the molecularly chemisorbed and dissociatively chemisorbed states have positive binding energies. The binding energies of the molecular chemisorption states, MCV and MCB, are, respectively, 1.11 and $1.02 \mathrm{eV}$, while the binding energies of the dissociative chemisorbed states DCV and DCB are, respectively, 2.18 and $2.15 \mathrm{eV}$. The lowest energy configuration of $\mathrm{NH}_{3}$ adsorbed on $\mathrm{Ti}_{2}(\mathrm{Bz})_{2}$ is the DCV state and has a spin triplet electronic configuration. The DCB state has a multiplicity of 1 and lies $30 \mathrm{meV}$ lower in binding energy than the DCV state. The interatomic distance between $\mathrm{N}$ and nearest $\mathrm{Ti}$ atom is $1.93 \AA$, and that between the top Ti atom and its nearest $\mathrm{H}$ atom is $1.75 \AA$. These distances are close to the sum of the atomic radii of corresponding atoms. The dissociative chemisorbed state $\mathrm{NH}_{3}$ fragments into $\mathrm{NH}_{2}$ and $\mathrm{H}$ with the $\mathrm{H}$ atom binding to the top $\mathrm{Ti}$ atom. The distance between the $\mathrm{H}$ and the $\mathrm{N}$ in $\mathrm{NH}_{2}$ specie is $2.80 \AA$, which is much longer than that in $\mathrm{NH}_{3}$ molecule of $1.02 \AA$.

The physisorption and the molecular chemisorption states of $\mathrm{NH}_{3}$ on $\mathrm{Ti}(\mathrm{Bz})_{2}$ complex have their binding ener-

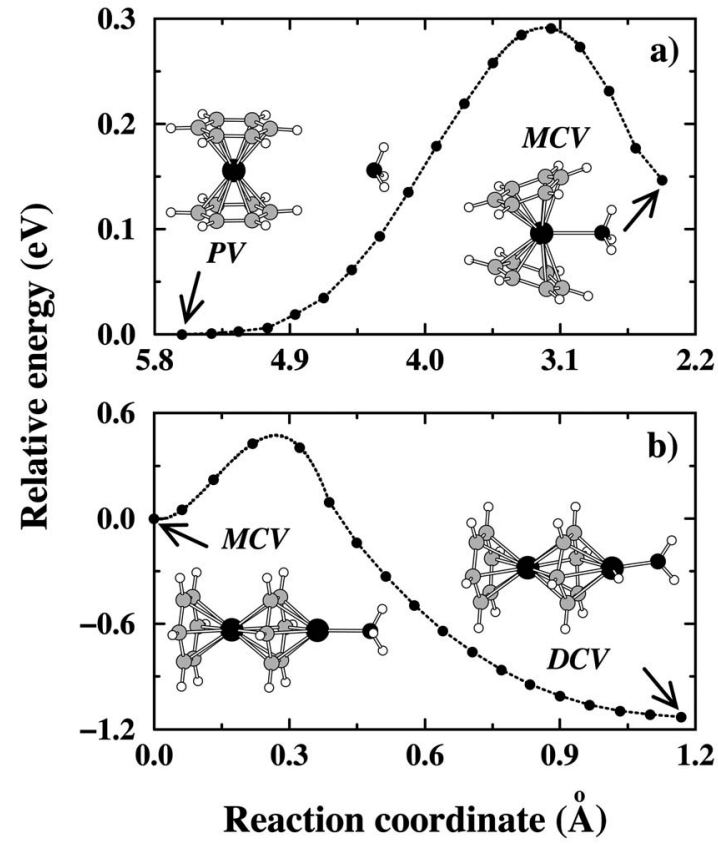

FIG. 2. Converged minimum energy paths calculated using the elastic band method. (a) The reaction path between the PV and MCV states for $\mathrm{NH}_{3}$ adsorbed $\mathrm{Ti}(\mathrm{Bz})_{2}$ complex. The total energy of PV state is used as the reference, and the interatomic distance between $\mathrm{Ti}$ and $\mathrm{N}$ atoms is used as the reaction coordinate; (b) the path between the MCV and DCV states for $\mathrm{NH}_{3}$ adsorbed $\mathrm{Ti}_{2}(\mathrm{Bz})_{2}$ complex. The total energy relative to that of $\mathrm{MCV}$ state is plotted, and the deviation of $\mathrm{N}$ atom from that of MCV state is plotted as the reaction coordinate.

gies differ only by about $0.16 \mathrm{eV}$. Thus by applying the pressure, it may be able to get $\mathrm{NH}_{3}$ molecularly adsorb on $\mathrm{Ti}(\mathrm{Bz})_{2}$. To study this possibility, calculations of the energy barrier between the molecular chemisorption and the physisorption states is needed. We calculated the energy barrier by using the elastic band method. ${ }^{27-30}$ In Fig. 2(a), we show the converged results for the reaction path between PV and MCV states. The interatomic distance between the Ti atom and the $\mathrm{N}$ atom is selected as the reaction coordinate, and the total energy relative to that of PV state is used to measure the energy barrier. The energy barrier from the molecularly chemisorbed (MCV) state to the physisorbed (PV) state is only $0.14 \mathrm{eV}$, which could be easily overcome, and hence it may be difficult to trap the molecule in the MCV state. Thus in an experiment, once the molecular chemisorbed state is produced, a small perturbation such as heat could easily allow it to overcome the barrier to PV state, and hence it will be difficult to observe the binding of $\mathrm{NH}_{3}$ to $\mathrm{Ti}(\mathrm{Bz})_{2}$ complex. Figure 2(b) shows the converged minimum energy path between MCV and DCV states of $\mathrm{NH}_{3}$ adsorbed on $\mathrm{Ti}_{2}(\mathrm{Bz})_{2}$ complex. The $\mathrm{Ti}_{2}(\mathrm{Bz})_{2}$ complex, due to the exposed $\mathrm{Ti}$ atom, reacts with the $\mathrm{NH}_{3}$ molecule. The energy barrier between the above two states is calculated to be $0.43 \mathrm{eV}$. This small barrier can be overcome leading to the formation of the dissociative chemisorbed state as the final configuration. Experiment shows that $\mathrm{Ti}_{n} \mathrm{Bz}_{n}$ complexes are reactive, and this agrees with our theoretical result.

\section{B. $\mathrm{H}_{2}$ adsorbed Ti-benzene complexes}

In Fig. 3, the optimized structures of $\mathrm{H}_{2}$ adsorbed Ti-benzene complexes are presented. The PV and PB are the 


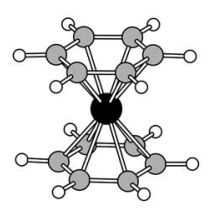

a), $P V, E_{\mathrm{b}}=0.02 \mathrm{eV}$

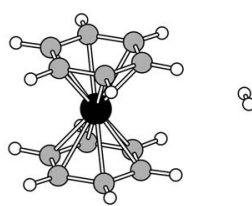

d), $P B, E_{\mathrm{b}}=0.02 \mathrm{eV}$

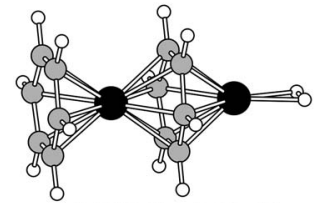

g), $M C V, E_{\mathrm{b}}=0.36 \mathrm{eV}$

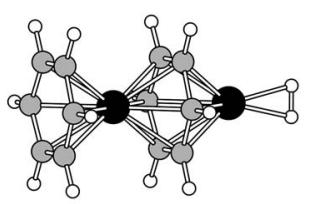

i), $M C B, E_{\mathrm{b}}=0.35 \mathrm{eV}$

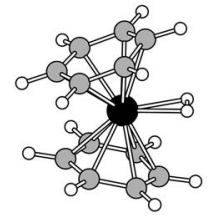

b), $M C V, E_{\mathrm{b}}=-0.17 \mathrm{eV}$

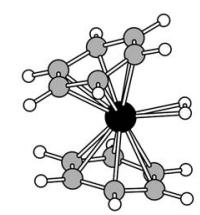

$e), M C B, E_{\mathrm{b}}=-0.13 \mathrm{eV}$

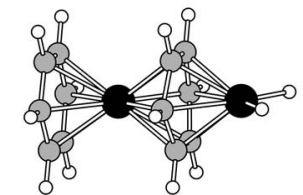

h), $D C V, E_{\mathrm{b}}=1.14 \mathrm{eV}$

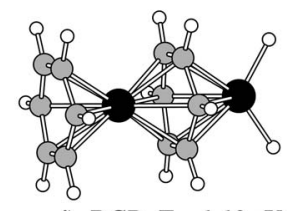

$j), D C B, E_{\mathrm{b}}=1.10 \mathrm{eV}$
FIG. 3. The optimized adsorption configurations of $\mathrm{H}_{2}$ adsorbed Ti-benzene complexes. The white, the gray, and the black balls represent $\mathrm{H}, \mathrm{C}$, and $\mathrm{Ti}$ atoms, respectively. (a) and (d) are the physisorption states for $\mathrm{Ti}(\mathrm{Bz})_{2}$; (b) and (e) are the molecular chemical adsorption states for $\mathrm{Ti}(\mathrm{Bz})_{2}$; (c) and (f) are the dissociative chemisorption states for $\mathrm{Ti}(\mathrm{Bz})_{2} ;(\mathrm{g})$ and (i) are the molecular chemical adsorption states for $\mathrm{Ti}_{2}(\mathrm{Bz})_{2}$; and $(\mathrm{h})$ and $(\mathrm{j})$ are the dissociative chemisorption states for $\mathrm{Ti}_{2}(\mathrm{Bz})_{2}$.

energetically preferred where $\mathrm{H}_{2}$ is physisorbed on $\mathrm{Ti}(\mathrm{Bz})_{2}$. Unlike the $\mathrm{NH}_{3}$, the different configurations do not affect the binding energies of $\mathrm{H}_{2}$ which are about $20 \mathrm{meV}$ in physisorption states due to its small size. The states corresponding to molecular chemisorption or dissociative chemisorption are higher and the structure of $\mathrm{Ti}(\mathrm{Bz})_{2}$ undergoes distortion. These chemisorption states have negative binding energies and hence are unstable. The interatomic distances between $\mathrm{Ti}$ atom and the $\mathrm{H}$ atom are $4.82 \AA$ in the $\mathrm{PV}$ state and $4.52 \AA$ in the PB state. The bond length of hydrogen molecule is $0.75 \AA$, while the bond length is elongated to $\sim 0.82 \AA$ in $\mathrm{MCV}$ and MCB configurations, and to $\sim 2.10 \AA$ in DCV and DCB configurations.

Analogous to that of $\mathrm{NH}_{3}$, the equilibrium structure of $\mathrm{H}_{2}$ interacting with $\mathrm{Ti}_{2}(\mathrm{Bz})_{2}$ complex is very different from that of $\mathrm{Ti}(\mathrm{Bz})_{2}$. There are no physisorbed states and the $\mathrm{H}_{2}$ molecule is chemisorbed either molecularly or disssociatively with the later being lower energy configuration. The molecular chemical adsorption states (MCV and $\mathrm{MCB}$ states) have binding energies of $\sim 0.36 \mathrm{eV}$, while the binding energies of the dissociative chemisorption states (DCV and DCB states) are $\sim 1.12 \mathrm{eV}$. The ground state spin multiplicity for the DCV state is 3 and that for the DCB state is 1. The interatomic distances of the hydrogen molecule in the MCV and MCB states are about $0.86 \AA$, while that in the DCV and DCB states are $\sim 2.97 \AA$. The distances between
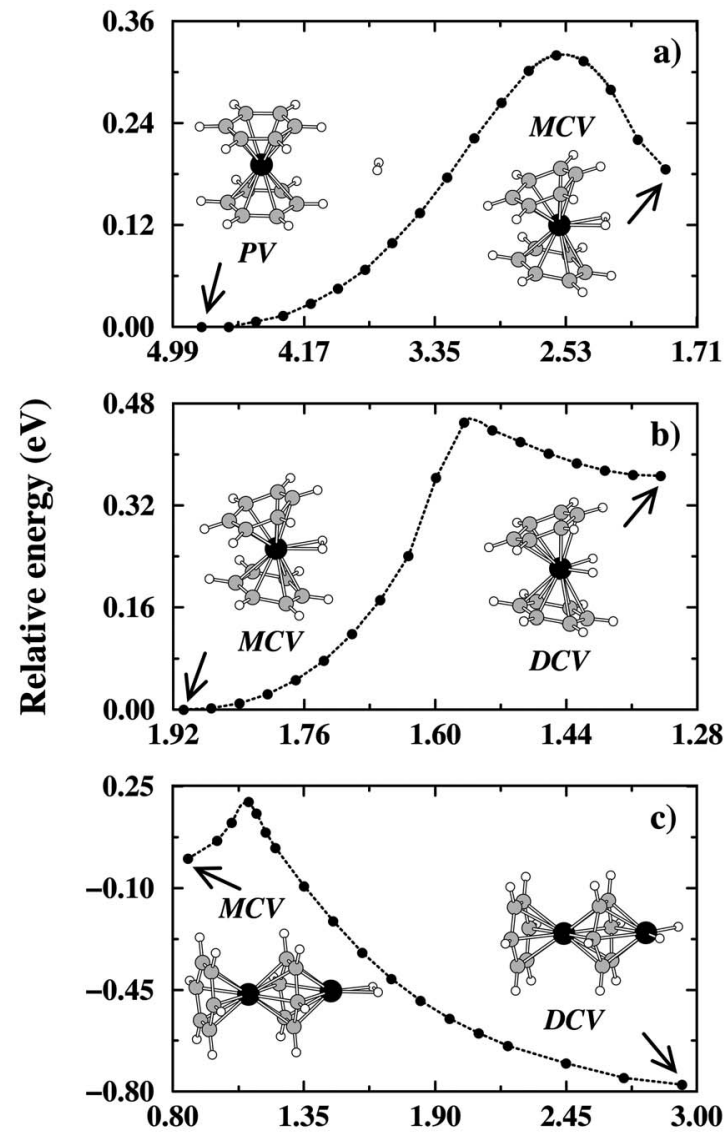

Reaction coordinate $(\stackrel{0}{\mathbf{A}})$

FIG. 4. Converged minimum energy paths calculated using the elastic band method. (a) The reaction path between the PV and MCV states for $\mathrm{H}_{2}$ adsorbed $\mathrm{Ti}(\mathrm{Bz})_{2}$ complex. The total energy of $\mathrm{PV}$ state is used as the reference, and the distance between $\mathrm{Ti}$ and the center of $\mathrm{H}-\mathrm{H}$ bond is used as the reaction coordinate; (b) the path between the MCV and DCV states for $\mathrm{H}_{2}$ adsorbed $\mathrm{Ti}(\mathrm{Bz})_{2}$ complex. The total energy of MCV state is the reference, the $\mathrm{H}-\mathrm{H}$ bond length is the reaction coordinate; (c) the reaction path between the MCV and DCV states for $\mathrm{H}_{2}$ adsorbed $\mathrm{Ti}_{2}(\mathrm{Bz})_{2}$ complex. The total energy relative to that of MCV state is plotted, and the $\mathrm{H}-\mathrm{H}$ bond length is plotted as the reaction coordinate.

the top $\mathrm{Ti}$ atom to the $\mathrm{H}$ atoms are $\sim 1.95 \AA$ in $\mathrm{MCV}$ and $\mathrm{MCB}$ configurations and $\sim 1.77 \AA$ in DCV and DCB configurations.

We have calculated the energy barriers between the PV and MCV states and between the MCV and DCV states by applying the elastic band method. The results are shown in Fig. 4. In Fig. 4(a) the total energy relative to that of the PV state for $\mathrm{H}_{2}$ adsorbed on $\mathrm{Ti}(\mathrm{Bz})_{2}$ is plotted as a function of the reaction coordinate taken as the distance between the center of $\mathrm{H}-\mathrm{H}$ bond and the Ti atom. The energy barrier for the MCV state to cross over to the PV state is $0.13 \mathrm{eV}$, while for transition of the PV state to the MCV state is $0.32 \mathrm{eV}$. These data show that under special experimental condition, the $\mathrm{H}_{2}$ molecule could be stored in the chemisorbed state and can be released only after a small perturbation.

In Fig. 4(b), we present the reaction path between MCV and $\mathrm{DCV}$ states for $\mathrm{H}_{2}$ adsorbed on the $\mathrm{Ti}(\mathrm{Bz})_{2}$ complex. The total energy of MCV state is used as a reference. The distance between the two $\mathrm{H}$ atoms is again used as the reaction coordinate. The results clearly show that the energy bar- 
riers for the transition from $\mathrm{MCV}$ to $\mathrm{DCV}$ and the reverse transition are 0.45 and $0.08 \mathrm{eV}$, respectively, which suggests that the hydrogen could be stored in dissociative chemical adsorption state under special conditions and the stored hydrogen could be released easily.

The converged reaction path between MCV and DCV states of $\mathrm{H}_{2}$ adsorbed on $\mathrm{Ti}_{2}(\mathrm{Bz})_{2}$ complex is shown in Fig. 4(c). The MCV state is used as the reference and the relative total energy is used to measure the energy evolution. The reaction coordinate is chosen as the distance between the two $\mathrm{H}$ atoms. The exposed $\mathrm{Ti}$ atom is reactive and incoming $\mathrm{H}_{2}$ binds to the top Ti atom. As shown by our structural optimization study, the dissociative chemisorbed state of $\mathrm{H}_{2}$ is the ground state, and the reaction process would release much heat due to the high binding energy. The incoming hydrogen molecule could bind in the molecular chemisorbed state and would transit to the final product of dissociative chemisorbed state by overcoming an $\sim 0.20 \mathrm{eV}$ energy barrier. The reverse process for releasing the hydrogen atoms adsorbed onto the Ti atom in DCV state has an $\sim 1.0 \mathrm{eV}$ energy barrier. The study of the reaction path shows that the $\mathrm{H}_{2}$ could be easily bind dissociatively to the exposed Ti atom, but it will be hard to release it. It is possible that successive $\mathrm{H}_{2}$ molecules to be bound to the exposed Ti atom with binding energies that will depend on of the number of attached molecules.

We have studied the dynamical properties of the above mentioned states by performing first-principles molecular dynamics (MD) simulation as implemented in VASP code. A microcanonical ensemble was used and the simulation lasted for 1 ps. We started the MD simulations at $500 \mathrm{~K}$ for the MCV and DCV states of $\mathrm{H}_{2}$ adsorbed on $\mathrm{Ti}(\mathrm{Bz})_{2}$, and for the MCV state of $\mathrm{H}_{2}$ adsorbed on $\mathrm{Ti}_{2}(\mathrm{Bz})_{2}$ (see the configurations shown as inserts in figure Fig. 4). The $\mathrm{H}_{2}$ in molecular chemisorption state $\mathrm{MCV}$ on $\mathrm{Ti}(\mathrm{Bz})_{2}$ flies away from the Ti atom and finally converges to the physisorption state PV during the simulation. The DCV state for $\mathrm{H}_{2}$ adsorbed on $\mathrm{Ti}(\mathrm{Bz})_{2}$ first evolves to the intermediate state $\mathrm{MCV}$ and then goes to the final product of the physisorption state PV. These results agree very well with our minimum energy path search which predicts that the energy barriers for the transitions from MCV to PV and DCV to MCV states for $\mathrm{H}_{2}$ adsorbed on $\operatorname{Ti}(\mathrm{Bz})_{2}$ complex are small and can be overcome at elevated temperatures. Similarly, the small energy barrier between the MCV and DCV states for $\mathrm{H}_{2}$ adsorbed on $\mathrm{Ti}_{2}(\mathrm{Bz})_{2}$ complex did not allow the MCV state to remain during the MD simulation. We also carried out MD simulation at 1500 $\mathrm{K}$ to further check the stability of the DCV state for $\mathrm{H}_{2}$ adsorbed on $\mathrm{Ti}_{2}(\mathrm{Bz})_{2}$ complex. Due to the high energy barrier found in our minimum energy path search, hydrogen atoms were trapped in the DCV state on the potential surface during the simulation. This suggests that it is hard to release hydrogen adsorbed in the dissociative chemisorption state DCV on a $\mathrm{Ti}_{2}(\mathrm{Bz})_{2}$ complex.

The above results show that $\mathrm{H}_{2}$ and $\mathrm{NH}_{3}$ can both be used to shed light on the structure of $\mathrm{T}-\mathrm{Bz}$ complexes. $\mathrm{Ti}_{n} \mathrm{Bz}_{n+1}$ complexes are not reactive while $\mathrm{Ti}_{n} \mathrm{Bz}_{n}$ complexes react. This establishes liner sandwich structures for these complexes.

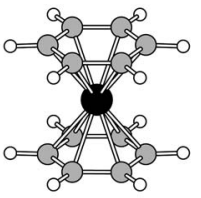

a), $P V, E_{\mathrm{b}}=0.08 \mathrm{eV}$

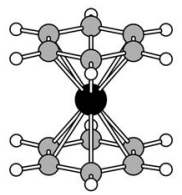

d), $P B, E_{b}=0.11 \mathrm{eV}$

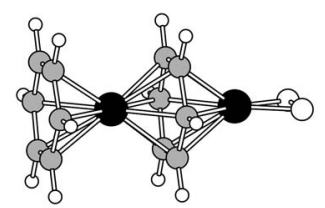

g), $M C V, E_{\mathrm{b}}=5.05 \mathrm{eV}$

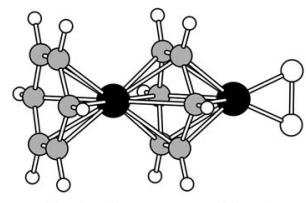

i), $M C B, E_{\mathrm{b}}=5.16 \mathrm{eV}$

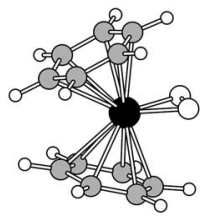

b), $M C V, E_{\mathrm{b}}=1.87 \mathrm{eV}$

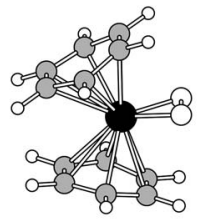

$e), M C B, E_{\mathrm{b}}=2.05 \mathrm{eV}$

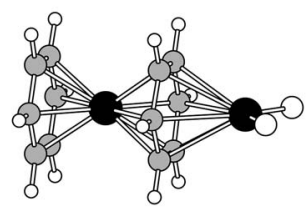

h), $D C V, E_{\mathrm{b}}=8.00 \mathrm{eV}$

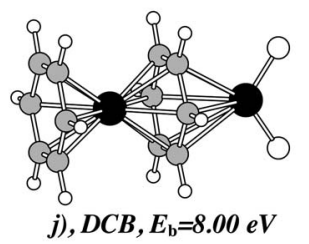

FIG. 5. The optimized geometries of $\mathrm{O}_{2}$ adsorbed Ti-benzene complexes. The small white, the big white, the gray, and the black balls represent $\mathrm{H}, \mathrm{O}$, $\mathrm{C}$, and Ti atoms, respectively. (a) and (d) are the physisorption states for $\mathrm{Ti}(\mathrm{Bz})_{2}$; (b) and (e) are the molecular chemisorption states for $\mathrm{Ti}(\mathrm{Bz})_{2}$; (c) and (f) are the dissociative chemisorption states for $\mathrm{Ti}(\mathrm{Bz})_{2} ;(\mathrm{g})$ and (i) are the molecular chemisorption states for $\mathrm{Ti}_{2}(\mathrm{Bz})_{2}$; and $(\mathrm{h})$ and $(\mathrm{j})$ are the dissociative chemisorption states for $\mathrm{Ti}_{2}(\mathrm{Bz})_{2}$.

\section{C. $\mathrm{O}_{2}$ interacting Ti-benzene complexes}

Finally, we have studied the reaction of $\mathrm{O}_{2}$ molecules with Ti-Bz complexes. The results are given in Fig. 5. The $\mathrm{O}_{2}$ molecule first physisorbs on the $\mathrm{Ti}(\mathrm{Bz})_{2}$ complex. In this state both $\mathrm{PV}$ and $\mathrm{PB}$ configurations gain $\sim 0.10 \mathrm{eV}$ binding energies. The configuration $\mathrm{PB}$ is a little higher in binding energy than the PV configuration. The highest binding energy state, however, is the dissociative chemisorption state. The $\mathrm{O}_{2}$ molecule dissociates and the $\mathrm{O}$ atoms bind to the $\mathrm{Ti}$ atom in $\operatorname{Ti}(\mathrm{Bz})_{2}$ complex. The different configurations $\mathrm{DCV}$ and DCB have the same binding energies of $5.09 \mathrm{eV}$ and the same spin singlet ground state. The molecular chemical adsorption states $\mathrm{MCV}$ and $\mathrm{MCB}$ for $\mathrm{O}_{2}$ adsorbed $\mathrm{Ti}(\mathrm{Bz})_{2}$ also have intermediate binding energies of 1.87 and $2.05 \mathrm{eV}$, respectively. The Ti-O distances are about $4.79,1.92$, and $1.68 \AA$ in physisorption states, molecular chemisorbed states, and dissociative chemisorbed states, respectively. The $\mathrm{O}-\mathrm{O}$ bond length is elongated from $1.26 \AA$ in physisorbed state to $1.45 \AA$ in molecular chemisorbed states, and finally reaches the $2.75 \AA$ in dissociative chemisorption states. The length of $\mathrm{O}-\mathrm{O}$ bond in the molecular chemisorbed state, namely, $1.45 \AA$, agrees very well with the peroxo bond of $1.45 \AA$ in the $\mathrm{TiO}_{2}$ complex. ${ }^{31}$ The chemisorbed configuration of $\mathrm{Ti}(\mathrm{Bz})_{2}$ complex experiences the largest distortion.

Figures $5(\mathrm{~g})-5(\mathrm{j})$ show the structures of $\mathrm{O}_{2}$ adsorbed onto the top $\mathrm{Ti}$ atom of $\mathrm{Ti}_{2}(\mathrm{Bz})_{2}$ complex. The molecular 
chemisorptions states $\mathrm{MCV}$ and $\mathrm{MCB}$ have higher binding energies than those of $\mathrm{Ti}(\mathrm{Bz})_{2}$ complex, which are $\sim 5.11 \mathrm{eV}$ on average. The dissociative chemisorption states DCV and DCB have the largest binding energies of $8.00 \mathrm{eV}$. The interatomic distances between two $\mathrm{O}$ atoms are 1.49 and $2.79 \AA$ for the molecular chemisorption state and the dissociative chemisorption states, respectively. The ground state spin multiplicities of the DCV and DCB states are singlet.

The best $\mathrm{O}_{2}$ adsorption state on Ti-benzene complex is the dissociated chemisorbed state. To understand the oxidation process of Ti-benzene complex, we have performed detailed calculations using the elastic band method of the minimum energy paths between the $\mathrm{PB}$ and $\mathrm{MCB}$ states and the MCB and DCB states for $\mathrm{O}_{2}$ adsorbed $\mathrm{Ti}(\mathrm{Bz})_{2}$ complex and between the MCB and DCB states for $\mathrm{O}_{2}$ adsorbed $\mathrm{Ti}_{2}(\mathrm{Bz})_{2}$ complex. The total energy was found to decrease smoothly starting from the $\mathrm{PB}$ state toward the MCB state for $\mathrm{O}_{2}$ on $\mathrm{Ti}(\mathrm{Bz})_{2}$. However, the converged results did not show any energy barrier. We therefore carefully double checked the PB state for $\mathrm{O}_{2}$ on $\mathrm{Ti}(\mathrm{Bz})_{2}$ and confirmed that $\mathrm{O}_{2}$ could exist in the physisorbed state. While a dense image elastic band calculation could be used to calculate the barrier, it is computer intensive. Therefore, we estimated the barrier by interpolating 31 points between the $\mathrm{PB}$ and $\mathrm{MCB}$ states on potential surface and calculating the total energy of each image while keeping the position of the atoms fixed. The energy barrier is estimated to be only $0.06 \mathrm{eV}$ for transition from the PB state to the MCB state. Since the interpolation method could overestimate the barrier, the real energy barrier could be very small, and the physisorbed state of the $\mathrm{O}_{2}$ molecule would evolve to the chemisorbed state almost spontaneously.

In Fig. 6(a) we plot the converged results based on the elastic band method between the MCB and DCB states for $\mathrm{O}_{2}$ adsorbed on $\mathrm{Ti}(\mathrm{Bz})_{2}$ complex. The total energy of $\mathrm{MCB}$ state is shifted to zero, and the relative energy is plotted as a function of the reaction coordinate which is the interatomic distance between two $\mathrm{O}$ atoms. The energy barrier is about $0.31 \mathrm{eV}$ from the MCB state to the DCB state. So, a small perturbation could drive the molecularly chemisorbed $\mathrm{O}_{2}$ molecule to dissociate into two separate oxygen atoms and bind to the Ti atom directly. The binding energies of the PB and DCB states are 0.11 and $5.09 \mathrm{eV}$, respectively. So, much heat would be released during the reaction.

For adsorption of $\mathrm{O}_{2}$ on the $\mathrm{Ti}_{2}(\mathrm{Bz})_{2}$ complex, our calculation again shows that there is no physisorbed state. The incoming $\mathrm{O}_{2}$ could be attached to the top Ti atom and release more than $5 \mathrm{eV}$ energy. Figure 6(b) presents the minimum energy path obtained by elastic band method for the evolution from the molecular chemisorption state MCB to the dissociative chemisorbed state DCB for $\mathrm{O}_{2}$ adsorbed on $\mathrm{Ti}_{2}(\mathrm{Bz})_{2}$ complex. The total energy relative to that of the MCB state is plotted. The reaction coordinate is the interatomic distance between two $\mathrm{O}$ atoms. One can see from the figure that the energy barrier is about $0.31 \mathrm{eV}$ for the $\mathrm{MCB}$ state transitioning to the DCB state. Therefore, once the $\mathrm{O}_{2}$ molecule is added to the $\mathrm{Ti}_{2}(\mathrm{Bz})_{2}$ complex, it would dissociate fast under a small perturbation. It is likely that when the incoming $\mathrm{O}_{2}$ molecule goes into the molecularly chemisorbed state, the heat released in the process would cause the

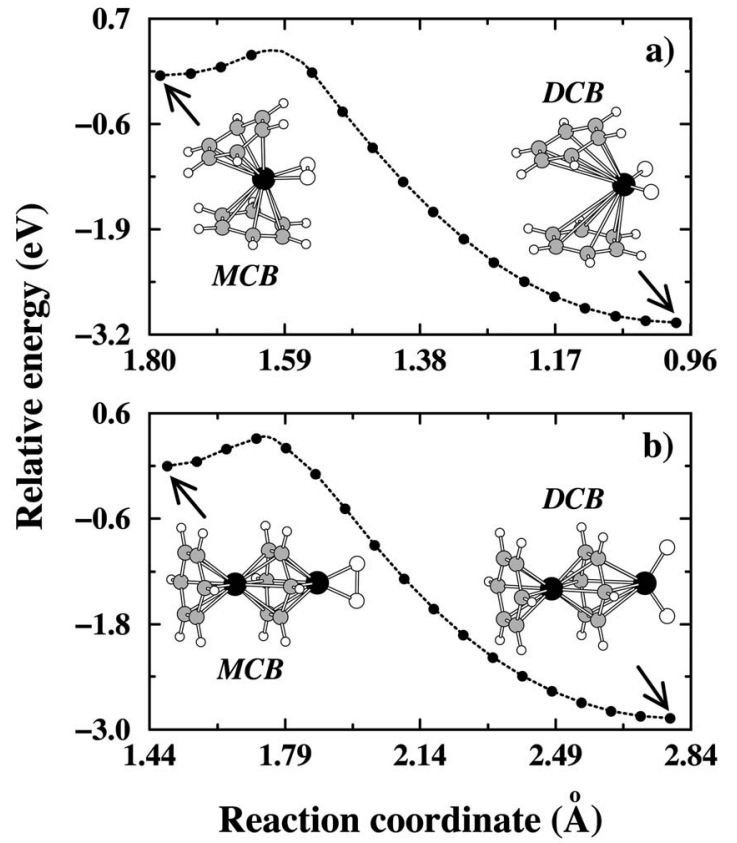

FIG. 6. Converged minimum energy paths calculated using the elastic band method. (a) The reaction path between the MCB and DCB states for $\mathrm{O}_{2}$ adsorbed $\operatorname{Ti}(\mathrm{Bz})_{2}$ complex. The total energy of MCB state is used as the reference, and the $\mathrm{O}-\mathrm{O}$ bond length is used as the reaction coordinate; (b) the path between the MCB and DCB states for $\mathrm{O}_{2}$ adsorbed $\mathrm{Ti}_{2}(\mathrm{Bz})_{2}$ complex. The total energy relative to that of $\mathrm{MCB}$ state is plotted, and the $\mathrm{O}-\mathrm{O}$ bond length is plotted as the reaction coordinate.

oxygen molecule to dissociate. The whole reaction would release about $8 \mathrm{eV}$ energy as the incoming free oxygen molecule dissociates chemisorbs.

\section{Electronic structure}

In Fig. 7(a), we plot the total density of states (DOS) of $\mathrm{Ti}(\mathrm{Bz})_{2}$. The DOSs for the $\mathrm{NH}_{3}, \mathrm{H}_{2}$, and $\mathrm{O}_{2}$ adsorbed on $\mathrm{Ti}(\mathrm{Bz})_{2}$ complexes corresponding to the highest binding energy structures are plotted in Figs. 7(b) $-7(\mathrm{~d})$, respectively. Similarly the DOS of $\mathrm{Ti}_{2}(\mathrm{Bz})_{2}$ and those with $\mathrm{NH}_{3}, \mathrm{H}_{2}$, and $\mathrm{O}_{2}$ adsorbed $\mathrm{Ti}_{2}(\mathrm{Bz})_{2}$ complexes are shown in Figs. $7(\mathrm{e})-7(\mathrm{~h})$, respectively. The dotted lines mark the Fermi energies.

The band gap between the highest occupied molecular orbital (HOMO) and the lowest unoccupied molecular orbital (LUMO) is $0.94 \mathrm{eV}$ for the bare $\mathrm{Ti}(\mathrm{Bz})_{2}$ complex. The $\mathrm{Ti}_{2}(\mathrm{Bz})_{2}$ complex due to the top $\mathrm{Ti}$ atom has zero band gap, which suggests that it should be more reactive. The $\mathrm{NH}_{3}$ and $\mathrm{H}_{2}$ do not chemisorb on $\mathrm{Ti}(\mathrm{Bz})_{2}$, however, they do react with the top $\mathrm{Ti}$ atom in $\mathrm{Ti}_{2}(\mathrm{Bz})_{2}$. For the weak van der Waals interaction, physisorption of $\mathrm{NH}_{3}$ and $\mathrm{H}_{2}$ on $\mathrm{Ti}(\mathrm{Bz})_{2}$ does not alter its DOS much and the band gaps of $\mathrm{NH}_{3}$ and $\mathrm{H}_{2}$ adsorbed on $\operatorname{Ti}(\mathrm{Bz})_{2}$ complexes are 0.95 and $0.94 \mathrm{eV}$, respectively. The highest binding energy state for $\mathrm{O}_{2}$ adsorbed $\mathrm{Ti}(\mathrm{Bz})_{2}$ is the dissociative chemisorbed state. The binding of oxygen to the titanium significantly affects the electronic properties of $\mathrm{Ti}(\mathrm{Bz})_{2}$. The band gap between HOMO and LUMO is enlarged to $2.0 \mathrm{eV}$. We have checked the band energies of the LUMO bands of freestanding $\mathrm{NH}_{3}, \mathrm{H}_{2}$, and $\mathrm{O}_{2}$ molecules, which are $-0.82,-0.01$, and $-4.96 \mathrm{eV}$, re- 


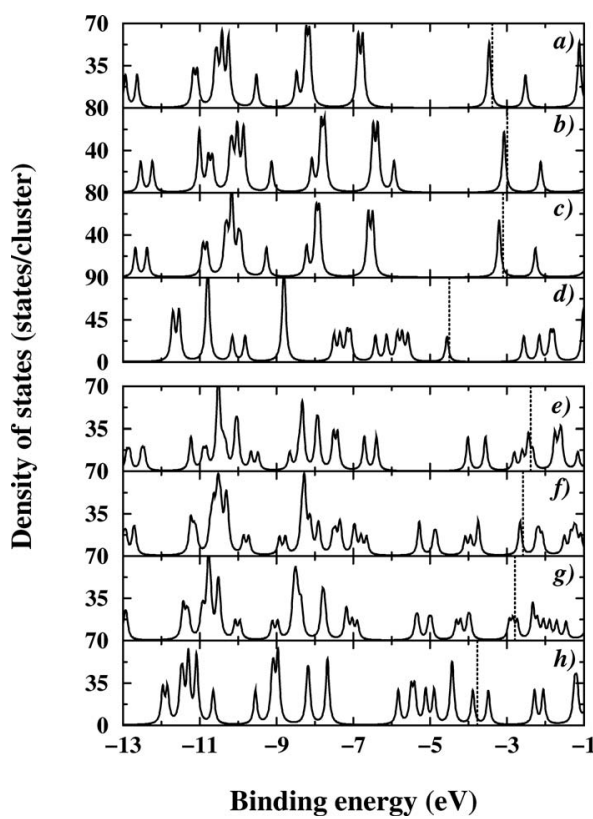

FIG. 7. DOS of (a) $\mathrm{Ti}(\mathrm{Bz})_{2}$ complex and those $[(\mathrm{b})-(\mathrm{d})]$ corresponding to the highest energy configurations of $\mathrm{NH}_{3}, \mathrm{H}_{2}$, and $\mathrm{O}_{2}$ molecules adsorbed $\mathrm{Ti}(\mathrm{Bz})_{2}$ DOS of $(\mathrm{e}) \mathrm{Ti}_{2}(\mathrm{Bz})_{2}$ complex and those $[(\mathrm{f})-(\mathrm{h})]$ corresponding to the highest binding energy configurations of $\mathrm{NH}_{3}, \mathrm{H}_{2}$, and $\mathrm{O}_{2}$ molecules adsorbed $\mathrm{Ti}_{2}(\mathrm{Bz})_{2}$.

spectively. When these molecules interact with the Ti atom, the valence electrons of Ti overlap with the LUMO orbital. The more negative is the LUMO band energy, more likely it is for the electron to be trapped in these orbitals. Among the above molecules, $\mathrm{O}_{2}$ has the lowest LUMO orbital, and as it interacts with the Ti atom, it binds strongly with the valence electron of the $\mathrm{Ti}$ atom. The oxygen molecule, therefore, is more reactive toward the Ti atom and is an important factor in understanding the different adsorption states.

As shown in Fig. 7(e), the $\mathrm{Ti}_{2}(\mathrm{Bz})_{2}$ complex has a band gap of only $0.10 \mathrm{eV}$ which accounts for its higher reactivity. We studied the band decomposed charge density of the HOMO band, which shows that the HOMO charge is mainly distributed around the top $\mathrm{Ti}$ atom which acts as a reactive site where the incoming species chemically adsorb. The $\mathrm{NH}_{3}, \mathrm{H}_{2}$, and $\mathrm{O}_{2}$ molecules are found to attach to the top Ti atom in dissociative chemisorbed states and release about 2, 1 , and $8 \mathrm{eV}$ energies, respectively. One can see from Figs. 7(f) $-7(\mathrm{~h})$ that the dissociative chemisorbed states of $\mathrm{NH}_{3}, \mathrm{H}_{2}$, and $\mathrm{O}_{2}$ do not alter the band gaps much. The band gaps are $0.43,0.11$, and $0.40 \mathrm{eV}$, which shows that these materials are still reactive. Thus, they could adsorb more $\mathrm{NH}_{3}, \mathrm{H}_{2}$, or $\mathrm{O}_{2}$ molecules. We first checked the active adsorption site by putting a hydrogen atom on either top of the $\mathrm{Ti}$ atom or on the center $\mathrm{Ti}$ atoms of the $\mathrm{Ti}_{2}(\mathrm{Bz})_{2}$ complex where $\mathrm{NH}_{3}, \mathrm{H}_{2}$, or $\mathrm{O}_{2}$ are dissociatively adsorbed. The structures were fully relaxed. Our results show that the hydrogen atom binds stronger to the top $\mathrm{Ti}$ atom, which suggests that the top Ti atom is still reactive. Additional $\mathrm{NH}_{3}, \mathrm{H}_{2}$, and $\mathrm{O}_{2}$ molecule were placed on the on-top Ti atom of the $\mathrm{Ti}_{2}(\mathrm{Bz})_{2}$ complex already bound to $\mathrm{NH}_{3}, \mathrm{H}_{2}$, or $\mathrm{O}_{2}$ in dissociative adsorbed state. The optimized results show that they could be adsorbed in chemisorption state. This agrees very well with the picture arrived from a band gap analysis.

\section{CONCLUSIONS}

Based on our detailed first-principles calculations, we found that $\mathrm{NH}_{3}, \mathrm{H}_{2}$, and $\mathrm{O}_{2}$ molecules react with $\mathrm{Ti}_{2}(\mathrm{Bz})_{2}$ complex, but are unreactive toward $\mathrm{Ti}(\mathrm{Bz})_{2}$ complex. On the other hand, oxygen reacts with both $\mathrm{Ti}(\mathrm{Bz})_{2}$ and $\mathrm{Ti}_{2}(\mathrm{Bz})_{2}$ complexes. There are no physisorption states for $\mathrm{NH}_{3}, \mathrm{H}_{2}$, and $\mathrm{O}_{2}$ interacting with the exposed $\mathrm{Ti}$ atom of the $\mathrm{Ti}_{2}(\mathrm{Bz})_{2}$ complex. They first bind in the molecularly chemisorbed state and the transit to the dissociative chemisorption state after overcoming a small energy barrier. The energy barriers for such transitions are about $0.43,0.20$, and $0.32 \mathrm{eV}$ for $\mathrm{NH}_{3}, \mathrm{H}_{2}$, and $\mathrm{O}_{2}$ adsorbed $\mathrm{Ti}_{2}(\mathrm{Bz})_{2}$, respectively. The binding energies for the ground states of $\mathrm{NH}_{3}, \mathrm{H}_{2}$, and $\mathrm{O}_{2}$ adsorbed $\mathrm{Ti}_{2}(\mathrm{Bz})_{2}$ are $2.18,1.14$, and $8.00 \mathrm{eV}$, respectively. Only $\mathrm{O}_{2}$ reacts with the Ti atom in the $\mathrm{Ti}(\mathrm{Bz})_{2}$ complex. The reaction energy barriers for the $\mathrm{O}_{2}$ transitioning from the physisorbed state to the molecularly chemisorbed state, and then to the final dissociative chemisorbed state, are about 0.06 and $0.51 \mathrm{eV}$, respectively. The final product of $\mathrm{O}_{2}$ adsorbed $\mathrm{Ti}(\mathrm{Bz})_{2}$ has a binding energy of $5.09 \mathrm{eV} . \mathrm{NH}_{3}$ and $\mathrm{H}_{2}$ prefer the physisorbed states on $\mathrm{Ti}(\mathrm{Bz})_{2}$ complex, whose binding energies are about 0.06 and $0.11 \mathrm{eV}$, respectively. Indicated by our minimum energy path search, under special conditions such as the high pressure, one may store hydrogen in chemisorbed states on $\mathrm{Ti}(\mathrm{Bz})_{2}$ complex. The energy barriers for transition of $\mathrm{H}_{2}$ from physisorbed to the molecularly chemisorbed state, and then to the dissociative chemisorbed state, are about 0.32 and $0.45 \mathrm{eV}$, respectively. The reverse reaction to release hydrogen needs to overcome about 0.08 and $0.13 \mathrm{eV}$ barriers for the transitions from the dissociative chemisorption state to the molecularly chemisorbed state and then to the physisorbed states. In $\mathrm{Ti}_{2}(\mathrm{Bz})_{2}$ complex, the first incoming molecule would reach the dissociative chemisorption state with two isolated $\mathrm{H}$ atoms attached to the top $\mathrm{Ti}$ atom. However, the release of these hydrogen atoms needs to overcome a large barrier of about $1 \mathrm{eV}$. Upon adsorption of hydrogen around the top $\mathrm{Ti}$ atom, the center $\mathrm{Ti}$ atom can attach hydrogen in a manner similar to the center $\mathrm{Ti}$ atom in $\mathrm{Ti}(\mathrm{Bz})_{2}$ complex. Therefore, under special condition, the $\mathrm{Ti}_{2}(\mathrm{Bz})_{2}$ could also store hydrogen by adsorbing $\mathrm{H}_{2}$ around the sandwiched Ti atom. The physisorption of $\mathrm{NH}_{3}$ and $\mathrm{H}_{2}$ on the $\mathrm{Ti}(\mathrm{Bz})_{2}$ complex has little effect on the DOS of the metal-benzene complex due to the weak van der Waals interaction. The chemisorption of $\mathrm{O}_{2}$ on $\mathrm{Ti}(\mathrm{Bz})_{2}$ induces a large distortion of the structure, consequently changing its DOS and opening a band gap of about $2 \mathrm{eV}$. The band gaps of the $\mathrm{NH}_{3}, \mathrm{H}_{2}$, and $\mathrm{O}_{2}$ adsorbed $\mathrm{Ti}_{2}(\mathrm{Bz})_{2}$ complexes are still very small, showing their reactivity.

\section{ACKNOWLEDGMENTS}

We thank the crew of the Center for Computational Materials Science of the Institute for Materials Research, Tohoku University for their continuous support of the SR11000 supercomputing facilities. G.C. also thanks the members of Professor Jena's group at Physics Department of Virginia Commonwealth University for the fruitful discussions. 
${ }^{1}$ G. Wilkinson, F. G. A. Stone, and E. W. Abel, Comprehensive Organometallic Chemistry (Pergamon, New York, 1982).

${ }^{2}$ C. J. Ma and D. A. Dougherty, Chem. Rev. (Washington, D.C.) 97, 1303 (1997).

${ }^{3}$ D. Braga, P. J. Dyson, F. Grepioni, and B. F. G. Johnson, Chem. Rev. (Washington, D.C.) 94, 1585 (1994).

${ }^{4}$ T. Kurikawa, H. Takeda, M. Hirano, K. Judai, T. Arita, S. Nagao, A. Nakajima, and K. Kaya, Organometallics 18, 1430 (1999).

${ }^{5}$ K. Hoshino, T. Kurikawa, H. Takeda, A. Nakajima, and K. Kaya, J. Phys. Chem. 99, 3053 (1995).

${ }^{6}$ T. Yasuike, A. Nakajima, S. Yabushita, and K. Kaya, J. Phys. Chem. A 101, 5360 (1997)

${ }^{7}$ R. Pandey, B. K. Rao, P. Jena, and M. A. Blanco, J. Am. Chem. Soc. 123, 3799 (2001).

${ }^{8}$ H. Lee, W. I. Choi, and J. Ihm, Phys. Rev. Lett. 97, 056104 (2006).

${ }^{9} \mathrm{~S}$. Li and P. Jena, Phys. Rev. Lett. 97, 209601 (2006).

${ }^{10}$ E. Durgun, S. Ciraci, W. Zhou, and T. Yildirim, Phys. Rev. Lett. 97, 226102 (2006).

${ }^{11}$ T. Yildirim and S. Ciraci, Phys. Rev. Lett. 94, 175501 (2005)

${ }^{12}$ Q. Sun, Q. Wang, P. Jena, and Y. Kawazoe, J. Am. Chem. Soc. 127, 14582 (2005).

${ }^{13}$ P. Hohenberg and W. Kohn, Phys. Rev. 136, B864 (1964).

${ }^{14}$ W. Kohn and L. Sham, Phys. Rev. 140, A1133 (1965).
${ }^{15}$ G. Kresse and J. Hafner, Phys. Rev. B 47, 558 (1993).

${ }^{16}$ G. Kresse and J. Furthmüller, Phys. Rev. B 54, 11169 (1996).

${ }^{17}$ G. Kresse and D. Joubert, Phys. Rev. B 59, 1758 (1999).

${ }^{18}$ P. E. Blöchl, Phys. Rev. B 50, 17953 (1994).

${ }^{19}$ G. Kresse and J. Furthmüler, The Guide of the Vienna ab-initio Simulation Package, Austria, 2007, available for download at http:// cms.mpi.univie.ac.at.vasp/.

${ }^{20}$ J. P. Perdew, in Electron Structure of Solids'91, edited by P. Ziesche and H. Eshrig (Akademie, Berlin, 1991), p. 11.

${ }^{21}$ J. P. Perdew and Y. Wang, Phys. Rev. B 45, 13244 (1992).

${ }^{22}$ F. Rabilloud, J. Chem. Phys. 122, 134303 (2005).

${ }^{23}$ A. K. Kandalam, B. K. Rao, P. Jena, and R. Pandey, J. Chem. Phys. 120, 10414 (2004).

${ }^{24}$ D. R. Lide, CRC Handbook of Chemistry and Physics 2004-2005 (CRC, Boca Raton, FL, 2005).

${ }^{25}$ G. Chung and M. S. Gordon, Organometallics 22, 42 (2003).

${ }^{26}$ J. C. Slater, J. Chem. Phys. 41, 3199 (1964).

${ }^{27}$ G. Mills, H. Jónsson, and G. K. Schenter, Surf. Sci. 324, 305 (1995).

${ }^{28}$ G. Henkelman and H. Jónsson, J. Chem. Phys. 113, 9978 (2000).

${ }^{29}$ G. Chen, X. G. Gong, and C. T. Chan, Phys. Rev. B 72, 045444 (2005).

${ }^{30}$ S. P. Chan, G. Chen, X. G. Gong, and Z. F. Liu, Phys. Rev. Lett. 87, 205502 (2001).

${ }^{31}$ L. Vaska, Acc. Chem. Res. 9, 175 (1976). 